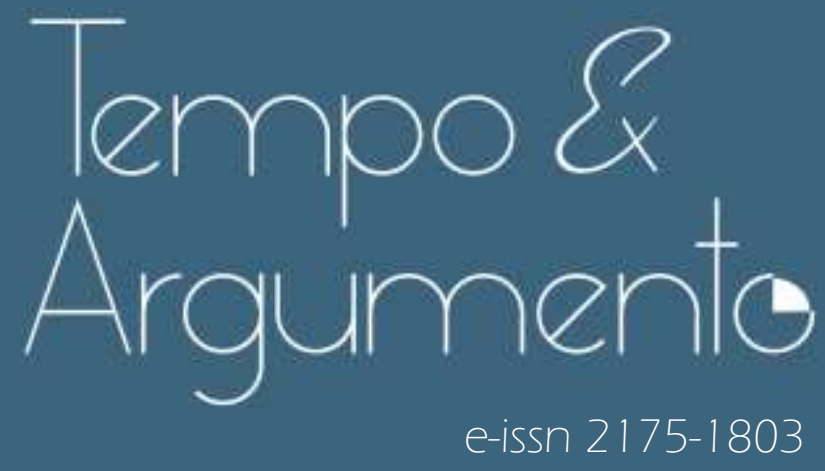

\title{
Koselleck, o sentido da história e o tempo presente
}

Resenha da obra:

KOSELLECK, Reinhart; GUMBRECHT, Hans Ulrich; RODRIGUES, Thamara de

Oliveira (org.). Uma latente filosofia do tempo. São Paulo: Editora Unesp, 2021.

- Renato de Araújo Monteiro

Doutorando em História Global na Universidade Federal de Santa Catarina (UFSC).

Florianópolis, SC - BRASIL

lattes.cnpq.br/3545492021814442

renatodearaujomonteiro@hotmail.com

(D) orcid.org/0000-0002-5278-8739

Para citar esta resenha:

KOSELLECK, Reinhart; GUMBRECHT, Hans Ulrich; RODRIGUES, Thamara de Oliveira (org.). Uma latente filosofia do tempo. São Paulo: Editora Unesp, 2021. Resenha de: MONTEIRO, Renato de Araújo. Koselleck, o sentido da história e o tempo presente. Revista Tempo e Argumento, Florianópolis, v. 13, n. 34, e0702. set./dez. 2021.

doi http://dx.doi.org/10.5965/2175180313342021e0702

Recebido: 19/11/2021

Aprovado: 20/12/2021 


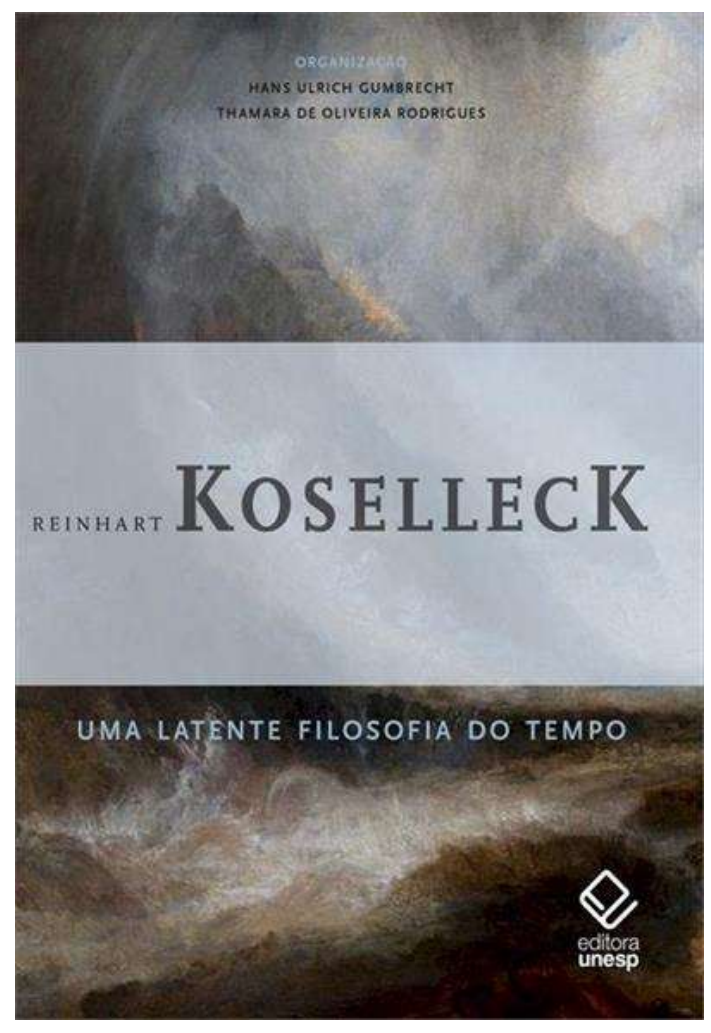

\author{
Resenha da obra: \\ KOSELLECK, Reinhart; GUMBRECHT, \\ Hans Ulrich; RODRIGUES, Thamara de \\ Oliveira (org.). Uma latente filosofia do \\ tempo. São Paulo: Editora Unesp, \\ 2021.
}

Com exceção ao clássico Crítica e crise e do menos conhecido Preußen zwischen reform und revolution [Prússia entre Reforma e Revolução], frutos de teses defendidas em 1954 e 1965, a obra do historiador Reinhart Koselleck é marcada por um caráter fragmentário, com artigos inicialmente publicados em revistas científicas e depois reunidos em coletâneas como Futuro Passado (1979), Estratos do Tempo (2000), História de Conceitos (2006) e Vom sinn und unsinn der geschichte, antologia póstuma organizada por Carsten Dutt em 2010. Há ainda os verbetes escritos para o Geschichtliche Grundbegriffe, o famoso dicionário de conceitos históricos do qual Koselleck foi também editor, entre 1972 e 1997. No Brasil, certa indiferença inicial pela sua obra foi seguida de um grande interesse. A Editora Contraponto publicou traduções completas de Crítica e crise (1999), Futuro passado (2006), Estratos do tempo (2014), e, mais recentemente, História de conceitos (2020). Em 2019, a Autêntica também publicou O conceito de História, retirado do segundo volume do dicionário (1975).

Uma latente filosofia do tempo (2021), por sua vez, que acaba de ser lançada pela Editora da Unesp, não corresponde à integra de qualquer livro anterior. Os quatro textos escolhidos por Hans U. Gumbrecht e Thamara Rodrigues, apesar de constarem em Vom sinn und unsinn der geschichte, com ela não se confundem. Ao todo, a versão de Dutt possui 22 capítulos, com "ensaios e palestras de quatro décadas", como anuncia o subtítulo. Trata-se, portanto, de obras com abrangência distintas, apesar de a edição brasileira conter o artigo que 
empresta título à congênere alemã, traduzido como Sobre o sentido e o não sentido da investigação histórica. No entanto, ao publicar textos nos quais Koselleck de certa forma é chamado, em diferentes momentos e por diferentes vias, a refletir sobre sua própria produção intelectual, o livro vem preencher uma lacuna que existia na biblioteca koselleckiana de língua portuguesa. Destaque para a apresentação de Thamara Rodrigues, que introduz as principais ideias do autor, assim como procura articulá-las com sua trajetória e o ambiente intelectual ao qual reagiu.

Apontado como um clássico desde sua aparição em 1971, Para que ainda investigação histórica? é o texto mais antigo do livro. Nele, Koselleck retoma a consideração intempestiva de Nietzsche, sobre as utilidades e desvantagens da história, para pensar a relação entre a crise do historicismo e o desprestígio da disciplina. Quase toda a argumentação se funda na distinção entre Historie e Geschichte, que já havia sido colocada no estudo de 1967 sobre a dissolução do topos da historia magistra vitae, e que seria complementada no verbete de 1975. Seguindo o posicionamento crítico ao Iluminismo de suas teses anteriores, Koselleck ataca o historicismo teleológico de Geschichte em detrimento da investigação científica advogada para a Historie.

Na sequência, o texto parte da noção heideggeriana de historicidade para compartilhar outro diagnóstico publicado por Koselleck naquele mesmo ano de 1971, que seria reeditado em Estratos do Tempo (2000) e se converteria em tese corrente: a indigência teórica da história e a necessidade de uma teoria da história (Historik) que desenvolvesse uma teorização dos tempos. Como possibilidades, indicava as regularidades formais elencadas por Karl Popper ou as "antropologias históricas" de Foucault e Van den Berg. Para além de seus objetivos imediatos, o artigo mostra como certas temáticas aparecem neste ainda início de trajetória do historiador. Antes mesmo da consolidação da história dos conceitos, por exemplo, já há uma forte aproximação com a linguística. Encontra-se também o problema da representação temporal por metáforas espaciais, assim como o fenômeno da simultaneidade do não-simultâneo e a noção das "camadas temporais", que inclui uma referência a Lévi-Strauss. Por outro lado, faz incursões por áreas menos exploradas, como ensino de história e interdisciplinaridade. 
Koselleck conclui com uma citação de Wilhelm von Humboldt sobre a forma universal da história, respondendo que as formas das histórias são suas temporalidades específicas. Assim, seu ensino e pesquisa serviriam para criticar a ideologia dos sentidos atribuídos à concepção singular (Geschichte), e também para elaborar uma teoria capaz de investigar as formas plurais (Historie), desde seus diferentes tempos e temporalizações. Em paralelo, a proeminência de Koselleck na progressiva sistematização da História dos Conceitos fará da linguagem cada vez mais o âmbito privilegiado de seus estudos. Aspecto este sopesado pela defesa e atenção às dimensões pré-linguísticas da história. Ainda no início dos anos 1970, suas intervenções no grupo Poetik und Hermeneutik, por exemplo, serão marcadas pela descrição de estruturas temporais e categorias formais que antecederiam articulações verbais. Ideias que constam em Futuro Passado (1979), mas seriam amadurecidas nos debates sobre hermenêutica travados com Gadamer na década de 1980, alguns republicados em Estratos do Tempo (2000).

De certo modo, foram essas relações entre experiência e linguagem, entre os limites de racionalidade e atribuição de sentido à história, que despertaram o interesse de Koselleck pelos sonhos no Terceiro Reich. Em 1971 e 1976 ele proferira polêmicas palestras sobre o tema, que também acabaram virando capítulo de Futuro Passado (1979) e artigo transcrito em 2007. É este texto, Ficção e realidade histórica, que reaparece agora em Uma latente filosofia do tempo. Ele questiona a antítese entre res factae, como pretenso objeto da história, e res fictae, como mera criação poética. A natureza híbrida dos sonhos, como algo não sucedido de fato, mas que antecipara o inverossímil do terror convertido mais tarde em evento, é usada para atestar o entrelaçamento entre ficção e facticidade. O texto novamente critica a concepção moderna de história, defendendo uma dimensão pré-verbal dos sonhos, a não correlação absoluta entre história e linguagem, e a ideia do poder de veto das fontes. Com Goethe, Koselleck alega não haver racionalidade na história acontecimento, senão na sua narrativa, cuja realidade deve ser sempre reescrita em função de novas experiências e da geração de novas expectativas. 
Em paralelo, o rigor conferido por Koselleck ao uso dos conceitos, concebidos como índices e fatores de mudança social, como realizações linguísticas saturadas de experiência, desde cedo o conduzira a uma busca por categorias - as mais formais possíveis - que pudessem metodologicamente descrever as condições antropológicas mais básicas do acontecer histórico, seu conhecimento e representação. Essas categorias encontram-se distribuídas de modo um tanto complexo na sua obra. Estruturas de repetição na linguagem e na história é um dos últimos textos que procura reorganizar algumas delas. Publicado no ano da sua morte, em 2006, é certamente também o mais vazado em terminologia antropológica. Contra a dicotomia entre sincronia e diacronia, Koselleck retoma uma tese de Estratos do Tempo (2000), sobre estruturas de repetição que possibilitam acontecimentos singulares. Sua proposta de representação em camadas destes padrões temporais inicia pelo que classifica como duas necessidades naturais: a condição humana atada à Terra e aquelas partilhadas com os animais, ponto que desdobra os pares adverbiais acima/abaixo, dentro/fora e antes/depois, aqui entendidos como de base biológica. A terceira é formada pelas instituições humanas de longa duração. Somente a quarta lida com pressupostos diacrônicos, mas que se valem de repetições para existir: planejamentos, prognósticos, profecias. A linguagem, quinta e última categoria, se diferencia pela estabilidade da gramática em contraposição à mutabilidade da semântica, por entre as quais se inscreve uma retórica/pragmática que atua em cada caso a partir de argumentos repetíveis.

Mas o artigo mais emblemático do livro é, sem sombra de dúvidas, Sobre o sentido e o não sentido da investigação histórica (Geschichte). Escrito em 1997, ele retoma algumas das questões debatidas quase três décadas antes em Para que ainda investigação histórica?, mas agora pode-se dizer que o motivador é a sua própria trajetória intelectual de crítica bem sucedida aos sentidos instituídos pelas filosofias teleológicas da história. As explicações para o absurdo da Batalha de Stalingrado, que já haviam sido discutidas em Fiç̧ão e realidade histórica, são utilizadas para recolocar uma primeira tese: a irracionalidade da história in actu e a razão histórica concebida apenas num complemento ex post de análise e narração. 
A segunda parte do texto reconhece que, da ênfase na pluralização de percepções, poderia resultar um perspectivismo subjetivista que desaguaria em teorizações narrativistas, como as de Hayden White. Contudo, Koselleck prefere passar da divergência de relatos para as suas condições de possibilidade, insistindo na ideia de que a história real é sempre mais e menos do que o contido em cada realização linguística consciente. Para ele, esse paradoxo não invalida o conhecimento histórico, tampouco se esgota em arquétipos literários, mas constitui um dado antropológico de transposição de experiências primárias em uma ciência temporalmente secundária, da qual a história emerge como um terceiro elemento. Dada essa diferença sempre reaberta, a história pressupõe uma provisoriedade da realidade que estabelece. Neste processo de constante reescrita, a variação das próprias categorias de percepção seria um problema de difícil controle metodológico. Problema este que só se torna pensável a partir da emergência do conceito moderno de história, que submeteu acontecimento e conhecimento a uma mesma condição teleologicamente estruturada. Em alemão, isso ocorrera no bojo da absorção do termo Historie por Geschichte. Mas Koselleck observa que, inclusive as línguas que não tiveram esse deslocamento lexical, sofreram pressões por mudanças semânticas semelhantes, mesmo mantendo vocábulos como histoire, historye, poderíamos acrescentar, "história".

Assim como fizera em Para que ainda investigação histórica?, a última parte usa Humboldt para descrever as reflexões contemporâneas à mudança transcendental da concepção moderna de história. Também aborda o fenômeno do historicismo que a ela se seguiu, com as atribuições de sentidos formulados por ideologias concorrentes, e novamente apresenta as considerações intempestivas de Nietzsche como uma das primeiras críticas aos principais axiomas teleológicos. Contudo, para Koselleck, ao colocar a história a serviço do conceito de vida, ele não deixou de atribuir-the uma finalidade, do mesmo modo como não resolveu o problema da ambiguidade entre acontecimento e conhecimento, ainda que tenha tido o mérito de promover uma reabertura para a pluralidade de possibilidades e sentidos. Os riscos de justificação da história são problematizados a partir das tentativas de significar a reaproximação francoalemã, em relação à experiência da guerra, e da criação do Estado de Israel, em 
relação ao Holocausto. O que não impediria, entretanto, o esforço de investigar o que pode fazer sentido para nós. E conclui: "a história não é um tribunal, nem muito menos um álibi”.

Para finalizar, há duas balizas que recortam os estudos de Koselleck, o período designado Sattelzeit, na virada para o século XIX, e a Segunda Guerra Mundial que, não por acaso, situa o início da Zeitgeschichte, variante alemã da História do Tempo Presente. Ainda que de modo aporético, neste ensaio sobre o sentido da história ele chega a afirmar que "o passado deve ser para nós passado antes que possa dar a conhecer sua verdade histórica". Porém, sua concepção de tempo, atualizada em função dos deslizamentos entre experiência e expectativa, faz do presente o lugar fundamental de possibilidade do conhecimento histórico. Talvez resida aí, na necessidade incontornável de reescrita, a prática de uma história do presente atenta não apenas aos acontecimentos mais recentes, mas às suas estruturas temporais, práticas de temporalização e atribuições de sentido. Em suma, um deslocamento de ênfase, do "presente" ao "tempo". 